\section{Accessory cardiac bronchus presenting with haemoptysis}

Michael P Keane, James F M Meaney, Ella A Kazerooni, Richard I Whyte, Andrew Flint, Fernando J Martinez

\begin{abstract}
The case history is presented of a 50 year old man with a two year history of haemoptysis secondary to an accessory cardiac bronchus.
\end{abstract}

(Thorax 1997;52:490-491)

Keywords: accessory cardiac bronchus, haemoptysis, bronchoscopy, computed tomography.

The accessory cardiac bronchus is a poorly recognised, usually asymptomatic, congenital anomaly of the bronchial tree. ${ }^{1-10}$ We describe the case history of a patient with an accessory cardiac bronchus who presented with haemoptysis in whom the diagnosis was delayed because of failure to recognise this uncommon congenital anomaly.

\section{Case report}

A 50 year old man presented with a two year history of recurrent haemoptysis. Chest radiography, bronchoscopy on two occasions, and computed tomographic (CT) scanning of the thorax $(10 \mathrm{~mm}$ thick contiguous images) revealed no abnormality to account for his symptoms.

Because of the failure to find a cause for the haemoptysis and the absence of objective findings, the possibility of factitious haemoptysis was considered. However, during an outpatient visit the patient expectorated approximately $200 \mathrm{ml}$ of blood in view of his physician. Bronchoscopic examination $30 \mathrm{~min}-$

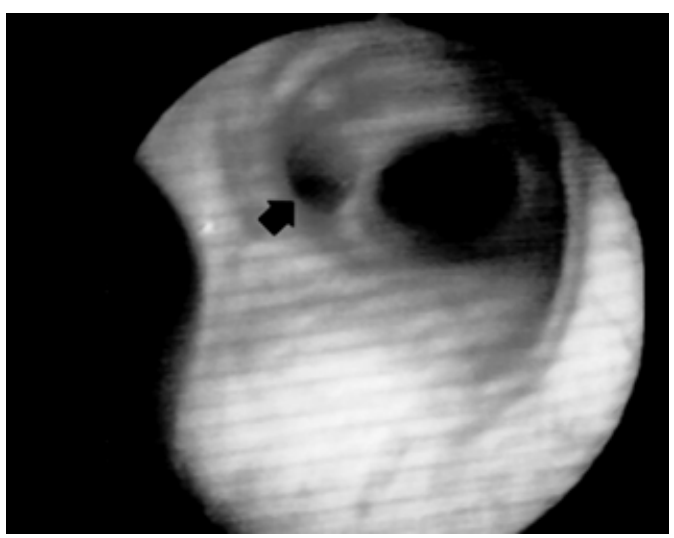

Figure 1 View through the bronchoscope showing an anomalous orifice (arrow) arising from the medial wall of the bronchus intermedius.

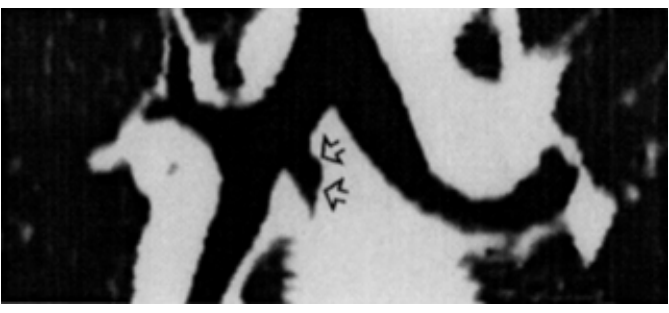

Figure 2 Coronal reconstruction of the helical slices showing the accessory cardiac bronchus (open arrows) arising from the medial wall of the bronchus intermedius and ending as a blind diverticulum.

utes later revealed an accessory bronchial orifice containing fresh blood arising from the medial wall of the bronchus intermedius at the level of the right upper lobe bronchus (fig 1). The remainder of the bronchial tree was normal. A subsequent spiral CT scan of the airways with multiplanar and threedimensional reformats confirmed the presence of an anomalous bronchus arising from the medial wall of the bronchus intermedius and descending inferomedially towards the heart (figs 2 and 3). A retrospective review of the axial CT images from the routine CT scan performed with $10 \mathrm{~mm}$ thick images showed an additional bronchus arising medially from the bronchus intermedius (fig 4). There was no identifiable lung tissue surrounding the bronchus.

The patient underwent a right thoracotomy and was found to have a small bronchus arising from the right main bronchus immediately opposite the origin of the right upper lobe bronchus. The anomalous bronchus extended medially into the subcarinal area and ended blindly approximately $3 \mathrm{~cm}$ from its origin. The bronchus was resected and the main bronchus closed with sutures. Pathological examination of the resected specimen revealed a distorted bronchus surrounded by aggregates of chronic inflammatory cells and fibrous tissue. A portion of the mucosa was inflamed and focally ulcerated. Collections of neutrophils were pres-

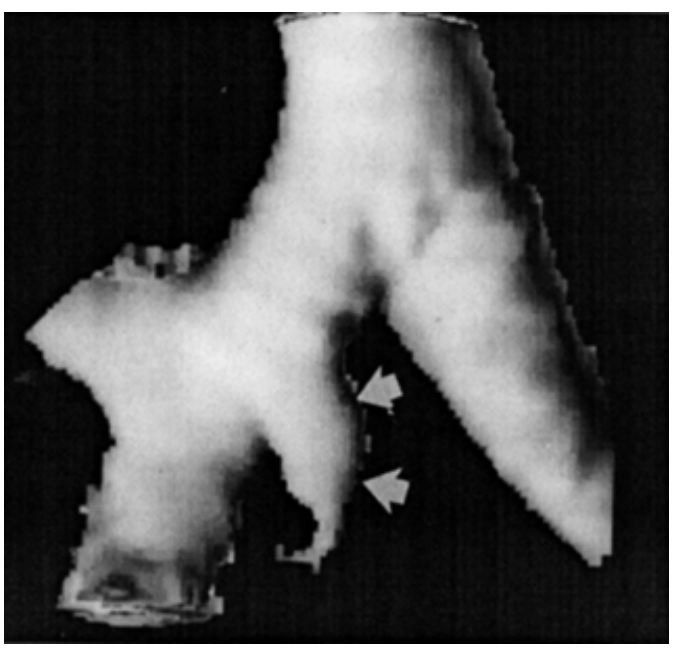

Figure 3 Surface rendered three-dimensional reconstruction showing the relationship of the accessory cardiac bronchus (arrows) to the remainder of the bronchial tree.

\author{
Revised version received \\ 2 May 1996 \\ Accepted for publication \\ 23 May 1996 \\ Internal Medicine, \\ M P Keane \\ J F M Meaney \\ Department of \\ Surgery, Section of \\ R I Whyte \\ Pathology \\ University of Michigan \\ Ann Arbor, Michigan \\ 48109-0360, USA \\ Dr F J Martinez. \\ Received 23 October 1995
}




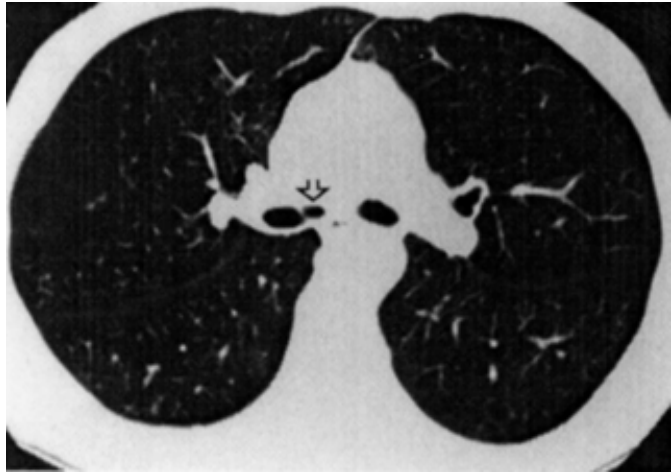

Figure 4 Axial image from the standard computed tomographic scan showing the accessory cardiac bronchus (open arrows) arising from the medial wall of the bronchus intermedius. There is no lung tissue surrounding the bronchus.

ent within the lumen of several small bronchial branches.

\section{Discussion}

The accessory cardiac bronchus (ABC) first described by Brock is the only true supernumerary anomalous bronchus, with a reported incidence of $0.09-0.5 \% .^{12}$ Two types have been described depending on whether or not there is associated lung tissue. In cases in which a cuff of lung tissue is present the bronchus tends to be a longer branching structure, whereas in cases where no lung tissue is observed the bronchus tends to be shorter and appears as a bronchial stump. ${ }^{3-5}$ An abnormal area of circumbronchial enhancing tissue which has been attributed to vestigial vascularised bronchial or parenchymal tissue and which does not represent normal lung tissue may be seen on the CT scan. ${ }^{4}$ Although the anomaly usually presents as an isolated finding, it has been associated with other abnormalities of the bronchial tree and in association with aberrant drainage of the right pulmonary artery directly into the left atrium. ${ }^{67}$

The infrequency of reports of accessory cardiac bronchus in the literature, despite a reported incidence of between one in 200 and one in 400 subjects, suggests that this anomaly remains silent in most cases. ${ }^{4}$ In a recent paper describing the CT features in six patients with accessory cardiac bronchus the finding was coincidental in four cases. ${ }^{4}$ Symptomatic cases frequently present with infection, probably due to pooling of secretions which become infected within the blind ending diverticulum. The predilection for middle lobe consolidation in association with this anomaly is explained by the anatomical juxtaposition of the middle lobe and accessory cardiac bronchi which arise close to one another on the lateral and medial walls of the bronchus intermedius, respectively. ${ }^{8}$

The accessory cardiac bronchus is not recognisable on plain chest radiographs, but may be demonstrated by bronchography, bronchoscopy, or CT scanning. ${ }^{34910}$ The CT scan and bronchoscopic features of accessory cardiac bronchus have been reported infrequently but its location is sufficiently characteristic to allow it to be recognised arising from the medial wall of the bronchus intermedius. In our case the anomalous bronchus was visible in retrospect on both previous CT scans, but it was missed prospectively by two separate thoracic radiologists. It was also missed at two previous bronchoscopic examinations carried out by independent operators. The failure to recognise the accessory cardiac bronchus at both bronchoscopy and CT scanning reflects ignorance of its occurrence, probably because of the low incidence of symptoms and subtle findings attributable to its presence. Nonetheless, the reported incidence of up to one in 200 subjects suggests that the anomaly should be encountered by busy bronchoscopic and chest CT services. Failure to recognise the characteristic disposition of the bronchus may result in delayed diagnosis. This can be avoided by recognition of the characteristic bronchoscopic and CT appearances and by acknowledging that accessory cardiac bronchus is a possible cause of haemoptysis and recurrent infection.

1 Brock RC. The anatomy of the bronchial tree. Oxford: Oxford University Press, 1946.

2 Mangiulea VG, Stinghe RV. The accessory cardiac bronchus. Bronchologic aspect and review of the literature. Dis Chest 1968;54:433-6.

3 Sotile SC, Brady MB, Brogdon BG. Accessory cardiac bronchus: demonstration by computed tomography. $\mathscr{F}$ Comput Tomogr 1988;12:144-6.

4 McGuinness G, Naidich DP, Garay SM, Davis AL, Boyd $\mathrm{AD}$, Mizrachi HH. Accessory cardiac bronchus: CT features and clinical significance. Radiology 1993;189: 563-6.

5 Beguery P, Denies JL, de Voogd A. Accessory cardiac bronchus. A report on a case and review of the published literature. I Radiol 1980;61:69-73.

6 Ameli M, Barone L. Unusual bronchial anomaly: association of tracheal bronchus and accessory cardiac association of tracheal bronchus and accessory carc
bronchus. Radiol Med (Torino) 1966;52:1152-60.

7 Kawada S, Koide S, Yamazki S, Shohtsu A, Kato S, Watabe $\mathrm{T}$, et al. Direct communication of the righ pulmonary artery and the left atrium associated with accessory cardiac bronchus. I fapan Assoc 1977;25 1497-503.

8 Daskalakis MK. Middle lobe syndrome due to accessory cardiac bronchus. South Med f 1983;76:941-2.

9 Atwell SW. An aberrant bronchus. Ann Thorac Surg 1966;2:438-41.

10 Stradling P. Diagnostic bronchoscopy: a teaching manual. 6th edn. Churchill Livingstone, 1991. 